\title{
TENTORIAL MENINGIOMAS
}

\author{
HOWARD S. BARROWS ${ }^{1}$ AND DONALD H. HARTER \\ From the Neurological Institute of New York and College of Physicians \\ and Surgeons, Columbia University
}

Tentorial meningiomas have been discussed in many articles devoted to meningicmas of the posterior fossa. Cushing and Eisenhardt (1938) described 15 cases, Campbell and Whitfield (1948) five cases, Russell and Bucy (1953) reviewed 46 cases from the literature and described two of their own, Castellano and Ruggiero (1953) presented 21 cases of tentorial meningioma, Markham, Fager, Horrax, and Poppen (1955) described seven cases, and Tristan and Hodes (1958) eight cases. Although these tumours are notorious for their ability to escape recognition clinically, a fact noted by many of the authors above, no detailed attempt has been made to characterize the clinical picture these meningiomas present. Despite their relative rarity, tentorial meningiomas leave a lasting impression when discovered at the time of radiography or surgery in a patient susfected of having a totally unrelated condition. Should these tumours present a characteristic pattern, earlier recognition might improve their prognosis.

Many different classifications for the location of meningiomas have been employed (Castellano and Ruggiero, 1953). However, in this survey tentorial origin was the only criterion used for selection.

Since the tentorium has a large intracranial area, tumours originating from it may vary widely in the actual location of their mass. Supratentorial, infratentorial, incisural, and posterolateral are terms that will be used to suggest the principal location of each tumour.

\section{MATERIAL}

Twenty-four cases of tentorial meningioma seen at the New York Neurological Institute from 1932 to 1960 were analysed. All were verified histologically as meningiomas and were seen to arise from the tentorium cerebelli at the time of operation or at post-mortem examination. Meningiomas arising principally from other sites in the posterior fossa

IOn a special traineeship award from the National Institute for Neurological Diseases and Blindness

Present address: Department of Neurology, University of Southern California, Los Angeles, California and involving the tentorium to a minor degree were excluded. Operative reports, radiographic reports, and radiographs were reviewed to determine, as accurately as possible, the location of each tumour. Correlations between clinical picture and anatomical site were attempted.

\section{RESULTS}

Tentorial meningiomas comprise $3 \%$ of the total number of meningiomas seen at the New York Neurological Institute during the period analysed. Nineteen of the tumours were in women and five were in men.

Eight of the tumours were seen to extend both supratentorially and infratentorially; the major growth, however, was in one direction. Clinically, $a \circ$ well-defined division was noted between those $\mathcal{D}$ tumours that were principally supratentorial and $\delta$ those which were principally infratentorial in location.

SUPRATENTORIAL MENINGIOMAS In eight patients extension occurred supratentorially (Table I), into the occipital lobe in four cases and into the temporal lobe in four cases. The clinical picture was that of a lateralized cerebral lesion, but its tentorial origin was rarely appreciated on admission. Patients with these tumours had the shortest duration of symptoms before admission. The cerebrospinal fluid, when examined, usually revealed normal pressure with an unquestionably raised protein level. The electroencephalogram pointed to the involved hemisphere with accuracy. Half of the patients were considered well two to 14 years post-operatively. There were two deaths.

INFRATENTORIAL MENINGIOMAS In sixteen of the twenty-four cases, tumour growth occurred infratentorially and provided the clinical enigma characteristic for tentorial meningiomas. Before radiography some of the clinical impressions were of multiple sclerosis, Arnold-Chiari malformation, Parkinsonism, frontal lobe tumour, and tic doulou- 
TABLE I

EIGHT CASES OF SUPRATENTORIAL MENINGIOMA

$\begin{array}{ll}\begin{array}{l}\text { Age range } \\ \text { Average }\end{array} & 18 \text { to } 65 \text { years } \\ \begin{array}{l}\text { Duration of symptoms } \\ \text { Average }\end{array} & 43 \text { months to } 4 \text { years } \\ \begin{array}{l}\text { Symptoms } \\ \text { Headache } \\ \text { Seizures } \\ \text { Weakness }\end{array} & 15 \text { months } \\ \begin{array}{l}\text { Signs } \\ \text { Homonymous hemianopsia }\end{array} & 7 / 8 \\ \begin{array}{l}\text { Papilloedema } \\ \text { Hemiparesis }\end{array} & 3 / 8 \\ \begin{array}{l}\text { Location } \\ \text { Temporal lobe }\end{array} & 5 / 8 \\ \text { Occipital lobe } & 5 / 8 \\ \begin{array}{l}\text { Spinal fluid } \\ \text { Protein } \\ \text { Pressure }\end{array} & 4 / 8 \\ \begin{array}{l}\text { Electroencephalogram } \\ \text { Abnormal }\end{array} & 4 \\ \text { Mortality } & 4 \\ \end{array}$

reux. Retrospective analysis of these cases suggested three clearly-defined clinical groups.

Group I This group of six patients presented the picture of obstructive hydrocephalus difficult to distinguish from that produced by other midline tumours (Table II). The average duration of symptoms was approximately four years, exceeding that of supratentorial meningiomas. Headache was

\section{TABLE II}

INFRATENTORIAL MENINGIOMAS IN GROUP I (SIX CASES)

$\begin{array}{ll}\begin{array}{l}\text { Age range } \\ \text { Average }\end{array} & 42 \text { to } 54 \text { years } \\ \begin{array}{l}\text { Duration of symptoms } \\ \text { Average }\end{array} & 7 \text { months to } 4 \text { years } \\ \begin{array}{l}\text { Symptoms } \\ \text { Headache }\end{array} & 2 \frac{1}{4} \text { years } \\ \begin{array}{l}\text { Blurred vision } \\ \text { Gait difficulty }\end{array} & 5 / 6 \\ \begin{array}{l}\text { Signs } \\ \text { Bilateral papilloedema }\end{array} & 3 / 6 \\ \begin{array}{l}\text { Cerebellar deficit } \\ \text { Dysmetria }\end{array} & 3 / 6 \\ \begin{array}{l}\text { Ataxia } \\ \text { Corticospinal tract deficit }\end{array} & 6 / 6 \\ \text { Location } & 6 / 6 \\ \text { Free edge of tentorium near midline } & 4 / 6 \\ \text { Cerebellar hemisphere } & 3 / 6 \\ \text { Spinal fluid } & 2 / 6 \\ \text { Protein } & 4 / 6 \\ \text { Pressure } & 29 \text { to } 102 \mathrm{mg} \text {. \% (four cases) } \\ \text { Mortality } & 140 \text { to } 270 \mathrm{~mm} \text {. (three cases) }\end{array}$

the principal complaint and bilateral papilloedema was a constant finding. They all de.nonstrated cerebellar signs. In three, the tumour was at the incisura close to the midline. In two, the mass was in the posterolateral recess of the tentorium involving the lateral sinus and compressing a cerebellar hemisphere. The remaining tumour was attached to the incisura more laterally but compressed the cerebellar hemisphere in its mid portion.

Plain skull films revealed demineralization of the dorsum sellae in four cases and upward displacement of the pineal in another. Air studies disclosed internal hydrocephalus in every case. The incisural midline tumours produced elevation of the posterior portion of the third ventricle.

In only one case was a marked left shift of the third ventricle and iter noted. Three of these patients died post-operatively. Of the remaining three, only one is functioning adequately. This group has the poorest prognosis. The following is an illustrative case for this group:

This 47-year-old white right-handed woman (C.B., Case 13) entered the New York Neurological Institute in July 1958 with complaints of decreased vision in her right eye and daily occipital headaches for over a year and a half before admission. In addition, she had noted unsteadiness in walking and some stiffness in the right arm and leg. On examination bilateral papilloedema and increased deep tendon reflexes with an extensor plantar response on the left were noted. Ventriculography revealed marked ventricular dilatation and upward displacement of the posterior third ventricle. A lumbar pneumoencephalogram showed air in the fourth ventricle, the cisterna magna, and the caudal portion of the iter. Needle biopsy of the tumour demonstrated a meningioma on histological examination. A ventriculopleural shunt was passed from the left ventricle into the right pleural cavity. This was followed by $4,000 \mathrm{r}$ of tumour radiation over a four-week period. On discharge the patient's gait and vision had improved.

The patient was re-admitted in June of 1959 with complaints of unsteadiness of gait and poor memory for one month. On examination she demonstrated a broad-based gait with decreased swing in the left arm. There was slight impairment in performing finger-to-nose and finger-to-finger movements bilaterally. Deep tendon reflexes were equal and hyperactive with a left extensor plantar response. A right upper quadrantanopia was elicited on testing visual fields associated with decreased acuity bilaterally. There was no evidence of papilloedema on this admission. Skull radiographs revealed demineralization of the dorsum sellae. Chest radiographs showed a small loculated pleural effusion at the right lateral costophrenicpleural reflection. A vertebral angiogram revealed marked separation of the right and left posterior cerebral arteries. Occipital craniotomy was performed with hypothermia. Ventricular fibrillation occurred during the procedure and the patient died.

Necropsy performed by Dr. Abner Wolf revealed a 
meningioma in the incisural notch arising from the tentorium of the cerebellum, with compression of the splenium of the corpus callosum, the ventral aspect of the temporal lobe, dorsal vermis of the cerebellum, quadrigeminal plate, anterior medullary velum, mid brain, pons, and iter. Marked dilatation of the lateral and third ventricles with a granulomatous granular ependymitis was noted. Histological examination revealed a highly compact meningioma.

Group II All six patients in this group presented with complaints referable to the trigeminal nerve (Table III). The average duration of symptoms before admission was slightly greater than five years.

\section{TABLE III}

INFRATENTORIAL MENINGIOMAS IN GROUP II (SIX CASES)

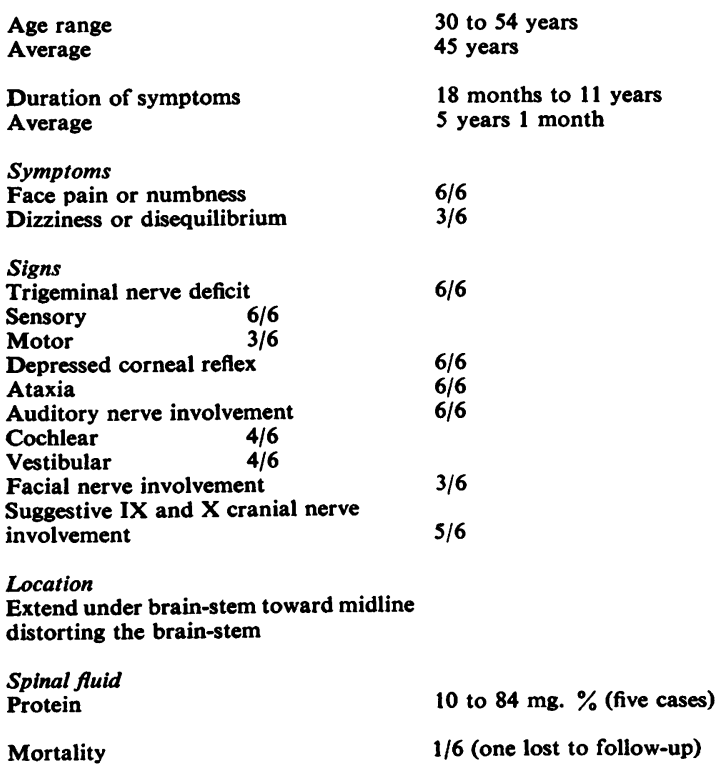

They demonstrated an objective sensory deficit over the face with a depressed corneal reflex. Pain and numbness in the face were the first symptoms to appear in all but one. Several patients were treated for tic douloureux. Four patients complained of deafness, and five of poor equilibrium or vertigo. All six demonstrated auditory nerve involvement, with abnormal calorics in four and deafness in five. Every patient demonstrated cerebellar deficit.

At the time of operation the tumour was seen to pass beneath the brain-stem near the cerebellopontine angle in every case. Distortion of the brainstem produced by the tumour was always noted.

Examinations of plain skull films were unrevealing except for a lateral shift of the pineal in one case and erosion of the base of the skull in another. The cere- brospinal fluid was examined in each patient; there was no raised pressure and the highest protein level was $84 \mathrm{mg}$. per $100 \mathrm{ml}$. Air contrast studies showed the posterior third ventricle and iter to be shifted forward and laterally in all but one case. In that case these structures were not seen. Four of these patients are alive and well after periods varying up to three years post-operatively. There was one death and one patient lost to follow-up. The following case is typical of this group:

This 54-year-old man (J.P., Case 17) was seen in the New York Neurological Institute in 1952, with complaints of 'tic-like' pain in the left side of the face. An avulsion of the left supraorbital nerve was performed. The patient still felt transitory pains in the left side of the face following this procedure. Two years before his admission he noted feelings of unsteadiness as though about to fall. The episodes lasted only a few seconds but became increasingly frequent before admission. Hissing in the left ear with decreased hearing bilaterally was noted since 1954, more marked on the left side. Skull radiographs performed in the out-patient department revealed bilaterally foreshortened petrous pyramids. In March 1959 the patient was admitted for possible bilateral acoustic neuromas. Examination showed a broad-based gait associated with mild ataxia and intention tremor on finger-to-nose testing bilaterally, with slowed succession movements. Bilaterally diminished corneal reflexes associated with diminished sensation over the first division of the left trigeminal nerve was found. Auditory acuity was diminished bilaterally with bone conduction less affected than air conduction. Nystagmus was noted on gaze bilaterally. A lumbar pneumoencephalogram revealed deviation of the posterior portion of the third ventricle, aqueduct, and anterior portion of the fourth ventricle to the right. The posterior portion of the floor of the third ventricle was displaced upward and a smooth indentation was seen in the left lower portion of the posterior part of the third ventricle. A left occipital craniotomy was performed and a left tentorial tumour partially removed that was seen to distort the lateral and ventral surface of the brain-stem. Histological examination revealed a highly-cellular meningioma with angioblastic features.

Nine months after the operation the patient was working regularly with some unsteadiness of gait and occasional 'electric-like' paraesthesias in the left corner of the mouth.

Group III The four patients in this group complained on admission of difficulties in walking (Table IV). Their average duration of symptoms was approximately two years, similar to group $I$. Examination showed the gait to be slow, stiff, and ataxic. All had cerebellar deficit. Three showed dysmetria and three ataxia. The tumours in this group had the largest part of their mass under the posterolateral recess of the tentorium. In addition, they were all seen to extend for a considerable distance, anteriorly to the incisura in three and 
TABLE IV

INFRATENTORIAL MENINGIOMAS IN GROUP III (FOUR CASES)

\begin{tabular}{|c|c|}
\hline $\begin{array}{l}\text { Age range } \\
\text { Average }\end{array}$ & $\begin{array}{l}55 \text { to } 60 \text { years } \\
57 \text { years }\end{array}$ \\
\hline $\begin{array}{l}\text { Duration of symptoms } \\
\text { Average }\end{array}$ & $\begin{array}{l}8 \text { months to } 4 \text { years } \\
2 \text { to } 2 \frac{1}{2} \text { years }\end{array}$ \\
\hline $\begin{array}{l}\text { Symptoms } \\
\text { Gait difficulty }\end{array}$ & $4 / 4$ \\
\hline $\begin{array}{l}\text { Signs } \\
\text { Gait difficulty } \\
\text { Slow mentation }\end{array}$ & $\begin{array}{l}4 / 4 \\
3 / 4\end{array}$ \\
\hline $\begin{array}{l}\text { Location } \\
\text { Most of tumour mass } \\
\text { hemisphere but with } \\
\text { to incisura (three ca } \\
\text { magnum (one) }\end{array}$ & \\
\hline $\begin{array}{l}\text { Spinal fluid } \\
\text { Protein }\end{array}$ & 31 to $91 \mathrm{mg}$. \% (four cases) \\
\hline Mortality & $1 / 4$ \\
\hline
\end{tabular}

posteriorly to the foramen magnum in one. On skull radiographs pineal shift was seen in one case, demineralization of the dorsum sellae in two cases. Examination of the cerebrospinal fluid was unrevealing in all cases. Air contrast studies showed hydrocephalus. The iter was displaced anteriorly and was angulated. In three the posterior portion of the third ventricle was deformed. The one death in this group was attributed to a post-operative myocardial infarction.

This 60-year-old woman (C.Mu., Case 24) entered the New York Neurological Institute in November 1953, complaining of difficulty in walking with stiffness of the legs and frequent loss of balance for six months. During this time she had urinary urgency with occasional loss of bladder control. More recently, she had become confused and disinterested. Examination revealed a stiff, spastic, wide-based gait with circumduction, more marked on the left than on the right. She could not walk on her toes or heels. Both lower extremities showed spastic and diffuse weakness. She fell backwards while standing with eyes closed. Plantar stimulation produced flexion of the left great toe and no reaction on the right. Vibratory sensation was poor in both lower extremities, position sense was intact. Cerebrospinal fluid examination revealed a protein of $33 \mathrm{mg} . \%$ with one white blood cell and a negative Kolmer reaction. An electrocardiogram on admission was within normal limits. Radiographs of the skull showed thickening of the base of the skull and a probable shift of the pineal to the left side. An electroencephalogram was within normal limits. Bilateral carotid arteriograms gave evidence of asymmetrical ventricular dilatation. Ventriculograms revealed generalized ventricular enlargement. The posterior part of the third ventricle and aqueduct deviated to the left and anteriorly. The right lateral ventricle showed a blunting of the posterior horn and atrium.
A right suboccipital craniotomy was performed and a subtentorial tumour partially removed. Histological examination revealed a highly cellular meningioma. Four days post-operatively the patient developed marked respiratory distress. Electrocardiography showed changes typical of an acute anterior myocardial infarction. She became cyanotic with periodic respirations and died five days post-operatively.

\section{DISCUSSION}

In this series of tentorial meningiomas, the ages and sex of the patients are not unusual and are similar to those reported in other series. Of the seven cases of tentorial meningioma reported by Markham et al. (1955) six appeared to fit into the clinical classifications outlined here. The remaining case more closely resembled a cerebellopontine angle meningioma. D'Errico's (1950) six cases of tentorium meningioma all fit group II. The three cases reported by Campbell and Whitfield (1948) and the one case of Russell and Bucy (1953) suggest the classifications mentioned here. The 15 cases of subtentorial and recess meningioma reported by Cushing and Eisenhardt (1938) were more advanced in their symptoms and signs than the patients in the present series. The average duration of symptoms before examination was five years. The clinical pictures they presented seemed too advanced to permit classification.

The infratentorial meningiomas of group I produced obstructive hydrocephalus by compression of the iter. Castellano and Ruggiero (1953) noted that meningiomas at the incisura in the midline compressed the iter directly, as in four cases of this group. They noted that meningiomas of more posterior attachment caused kinking of the iter by the forward advancing vermis as a result of pressure on the cerebellar hemisphere. This mechanism could explain the obstructive hydrocephalus seen in the remaining two cases of group I. Upper brain-stem compression probably contributed to the high mortality of these cases. This cannot be relieved by reduction of the intraventricular pressure. The patients in group I continued to deteriorate after ventriculopleural shunts were performed.

Group II is noteworthy for the long duration of symptoms of trigeminal involvement. Tentorial meningiomas should be suspected in patients with facial sensory complaints and objective evidence of trigeminal involvement. One case in this group had the fifth nerve findings on the side opposite to the tumour. This had been noted before (Cushing and Eisenhardt, 1938; Hamby, 1947; D'Errico, 1950; Castellano and Ruggiero, 1953; Russell and Bucy, 1953). Hamby observed the displaced pons to com- 
press the fifth nerve root against the incisura of the tentorium on the side opposite to the tumour. The additional involvement of the seventh, ninth, and tenth cranial nerves is not uncommon. D'Errico described this clinical syndrome in distinguishing tentorial meningioma from cerebellonontine angle meningioma. The anatomical location of the tumour mass in these cases is consistent; arising from the incisural margin laterally and extending toward the cerebellopontine angle, passing under the ventral surface of the brain-stem and distorting it noticeably. The long duration of isolated trigeminal symptoms suggests that the tumour originated at the incisural margin at or near the entrance of the trigeminal nerve into Meckel's cave.

The gait difficulty shown by the patients in group III may be caused by diffuse pressure on the brainstem, avoiding the severe obstruction of the iter and the early involvement of several cranial nerves characteristic of the other groups. The anatomical location of these tumours is not consistent throughout except for the generally more posterior locations of their mass and the extent of involvement. Extensive sessile tumours may only produce diffuse brain-stem pressure.

The longer duration of symptoms before admission to hospital in the patients belonging to the infratentorial group and the large size of the tumour found in the posterior fossa are testimony to the tremendous adaptakility of posterior fossa structures to a slowly expanding mass. Earlier recognition of these tumours, when their symptoms and signs are not disabling, should lead to earlier operation when the tumour is smaller and the risk of removal is less (D'Errico, 1950; Russell and Bucy, 1953).

\section{SUMMARY}

This survey of 24 cases of tentorial meningiona showed supratentorial meningiomas to present with a relatively short period of symptoms suggesting a lateralized cerebral mass lesion. One group of infratentorial tumours gave the picture of obstructive hydrocephalus and had a poor prognosis. Another infratentorial group produced a long history of trigeminal symptoms and demonstrated consistent involvement of the fifth and eighth cranial nerve systems. They had a better prognosis. A third infratentorial group featured a complex gait disturbance. All the infratentorial tumours presented signs of cerebellar involvement. Skull radiographs and spinal fluid examinations were generally not helpful in the infratentorial meningiomas. Meningiomas are histologically benign intracranial tumours and earlier clinical recognition should improve postoperative prognosis.

The authors wish to thank Dr. Juan Taveras for his helpful assistance with the radiographic studies, Dr. Abner Wolf for the use of the post-mortem material, and Dr. Melvin D. Yahr and Dr. H. Houston Merritt for their suggestions and assistance in preparation of the manuscript.

\section{REFERENCES}

Campbell, E., and Whitfield, R. D. (1948). J. Neurosurg., 5, 131.

Castellano, F., and Ruggiero, G. (1953). Acta radiol. (Stockh.), Suppl. 104.

Cushing, H., and Eisenhardt, L. (1938). Meningiomas, p. 181. Thomas, Springfield, Illinois.

D'Errico, A. (1950). J. Neurosurg., 7, 227.

Hamby, W. B. (1947). Ibid., 4, 179.

Markham, J. W., Fager, C. A., Horrax G and Poppen, J. L (1955). A.M.A. Arch. Neurol. Psychiat., 74, 163.

Russell, J. R., and Bucy, P. C. (1953). Surg. Gynec. Obstet., 96, 183. Tristan, T. A., and Hodes, P. J. (1958). Radiology, 70, 1. 